\title{
APPLICABILITY VERIFICATION OF AUTOFORM SOFTWARE FOR FEM SIMULATION OF MECHANICAL FIXATION OF HEMMED JOINTS
}

\author{
Lukáš ChrášŤanskÝ ${ }^{a, b, *}$, Jan ŠAnOVEC $^{a}$, Yatna YuWana MartaWirya $^{c}$, \\ Michal VALEŠ $\check{Y}^{a, b}$ \\ ${ }^{a}$ Czech Technical University in Prague, Faculty of Mechanical Engineering, Department of Manufacturing \\ Technology, Technická 4, 16607 Prague 6, Czech Republic

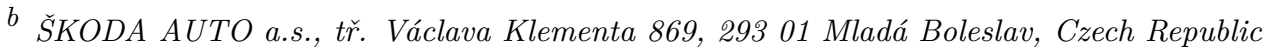 \\ ${ }^{c}$ ITB - Bandung Institut of Technology, Faculty of Mechanical and Aerospace Engineering Labtek II, 2nd Floor \\ Jl. E-ITB / Jl. Ganesha 10, 40132 Bandung, Indonesia \\ * corresponding author: Lukas.Chrastansky@fs.cvut.cz
}

\begin{abstract}
This paper deals with the problematics of fixation of hemmed joints, especially with one specific mechanical method how to ensure a dimensional stability of a hemmed joint of car-body parts, such as doors, bonnet and trunk lid, during the production process in the automotive industry. It also evaluates simulations and verify the possibility of the use of the Autoform software for this problematics. In the paper, the possibility of using the law of similarity in the analysis of the compressibility of small parts by Autoform is described.
\end{abstract}

Keywords: Hemming, FEM simulation, AutoForm, car-body, automotive industry, the law of similarity.

\section{INTRODUCTION}

Car-body production is a difficult complex task where many manufacturing technologies are used. Hemming is specific joining technology, which is commonly used during a car-body production in the automotive industry. One of the greatest challenges in the development of the car-body occurs during and after the hemming stage in the welding shop where all the car-body parts are assembled before painting. Car-body panel parts, such as doors, trunk lid and bonnet, are usually made from two main parts - inner metal sheet and outer metal sheet which are joined by hemming. During joining two or more sheets of metal plates together, the greatest challenge is to ensure a dimensional stability of sheet metal parts, which can move against each other. This negative effect can occur during other stages of production, especially during installation, when parts may not be correctly aligned. Due to the problems mentioned above, it is always necessary to use some fixation method of the hemmed joint to provide the dimensional stability. This article deals with a specific fixation method of hemmed joints and verification of the applicability of AutoForm software. This software is commonly used for FEM simulations during preparation stages for car-body parts production.

\section{FIXATION OF HEMMED JOINTS}

The Fixation of hemmed joints helps to stabilize the relative positions of the inner metal plate and outer metal plate during the manufacturing process until the parts go through the paint shop, where the main stabilizing function takes place in the form of a cured adhesive in hemmed joint applied the after cataphoretic painting. Fixation method further serves to maintain the desired dimensions of the final part during the hardening of the adhesive, which may temporarily cause different stresses due to the heat on the hemmed joint. Figure 1 is a representation of the possible movement of the inner sheet metal part against the outer part. The fixation is used to prevent such movement. [1, 2]

Unfortunately, this specific problematic is not described much in technical articles. Current methods of fixation are often developed by automotive companies that keep their know-how through patents and patent applications. Each of the different methods has its specific advantages and disadvantages, there are also differences in the applicability of the various methods, depending on the size, complexity and quality of the particular component. Because of all these mentioned reasons, a single suitable method as a universal one cannot be determined. Most common methods can be divided into two main groups. The methods based on a mechanical solution (some form of a mechanical lock) and methods which use some form of heat (brazing/ resistance spot welding/ adhesive curing). [3 8 ]

\subsection{MECHANICAL FIXATION OF HEMMED JOINT}

This specific solution envisages to prevent movement of the inner metal sheet against the outer metal sheet in both directions on the basis of a mechanical lock 


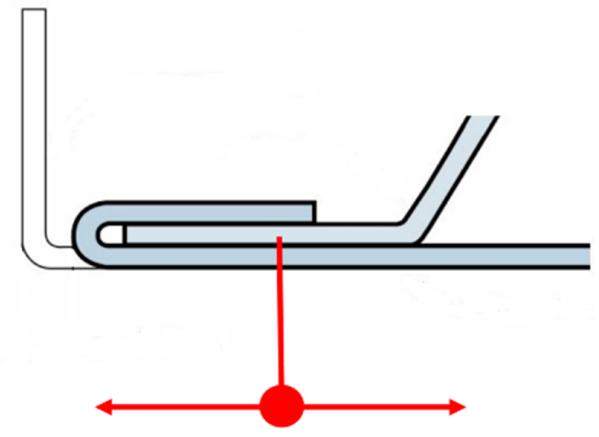

Figure 1. Possible movement of the inner part in hemmed joint.

(see Figure 2). By using a special puncher and die, small grooves around the whole circumference of the component on the inner metal plate are stamped. On the flange of the outer panel part, special small protrusions are stamped. These protrusions with the combination of grooves are making the mechanical lock after the hemming process, with using a plastic deformation, where the protrusion copies the shape of one of these grooves. This creates a strong joint with mechanical locking, and this leads to fixation of the mutual position of the joined parts during the hemming and the subsequent production process. 2, 9]

\section{DESCRIPTION OF EXPERIMENT}

This solution of the mechanical fixation is designed for use on steel metal sheets, which are used for a car-body 10. The specific material specification is shown below in Table 1 and Table 2, Different types of materials are used, due to different material requirements in practice on real parts. Chosen materials are typical for inner and outer parts of car-body in the automotive industry. The thickness of the sheet for both materials is $0.65 \mathrm{~mm}$.

To verify the applicability of the AutoForm software for a simulation of this problematics, it is necessary to prepare the simulation model with several operations (Fig 3).

The first operation deals with the preparation of the inner part for hemming. It includes stamping of the fixation element (grooving) on the inner part, with the use of special tools. It is necessary to export the simulation result as it is used for hemming.

The preparation of outer part includes two operations - flanging and stamping. Flanging consists in the bending of the sheet edge with an angle approximately equal to $90^{\circ}$. After flanging, the second step occurs, the stamping of protrusions on the flange of the outer part. In the same simulation task, the table hemming operation is prepared, so it is necessary to import the inner part and position it on the prepared outer part.

As the last step before simulation, it is necessary to set up the calculation method in the AutoForm software. A specific calculation method can influence the whole result in its accuracy. In this case, for the first operation (stamping on the inner part), 5 strategies were set up - CE (concept evaluation), CE+, FV (final validation), UD1 and UD2 (user-defined). All of the simulation strategy settings are shown below in Table 3 .

On the basis of the comparison of the simulation results, where tools with original dimensions have been used, it is clear that the software Autoform R6 has difficulties resulting in an inaccurate calculation of the numerical simulation for the $\mathrm{CE}$ and $\mathrm{CE}+$ strategy. According to Figure 4 it is clear that the quality of the output is not optimal, especially due to the specific settings. The current mesh elements are too large for the $\mathrm{CE}$ and $\mathrm{CE}+$ strategy. The tool is penetrating into the sheet and the sheet is not formed correctly.

The rest of the simulations $\left(\mathrm{FV}, \mathrm{UD}_{1}\right.$ and $\left.\mathrm{UD}_{2}\right)$ give much better graphical results, where the grooving profile is nicely formed. However, with regard to the FLD, it can be concluded that the continuation of the simulations with the original dimensions will not reveal the required results. If the current simulation result would be considered as a final result, it would lead to the conclusion that it is not possible to produce this grooving profile by the stamping process due to defects, which are detected in the Forming Limit Diagram (FLD) - see Figure 5 In case that the results would be relevant, it would lead to using this solution in practice.

The AutoForm software is mainly used for a simulation in the automotive industry for large car-body parts. Verification of such data can be done, for example, by the circular grid method [5].

Small and sharp geometries are difficult to simulate with the use of the AutoForm software as the used simulation model and material model cannot give relevant results. Therefore, another method for designing the methodology for numerical simulation of grooving stamping to get relevant results must be used. A possible solution for the trouble mentioned above can be applying one of the fundamental laws of plastic deformation, namely "Law of Similarity". [2, 11, 12,

\section{Simulation optimization}

As mentioned above, the possible solution is the use of the Law of Similarity. For the application, it is required to follow the definition of the law. The whole definition can be found in study texts ies [2, 12].

In this case, the same conditions are used to keep the mechanical and physical similarity. For geometrical similarity, it is necessary to modify the input parameters of the numerical simulation, in this case, the tool dimensions are increased in comparison to the original dimensions in the ratio of $10: 1$, including the thickness of the used metal sheet. Simulation strategy is based on FV (final validation) settings (see Table 3). 


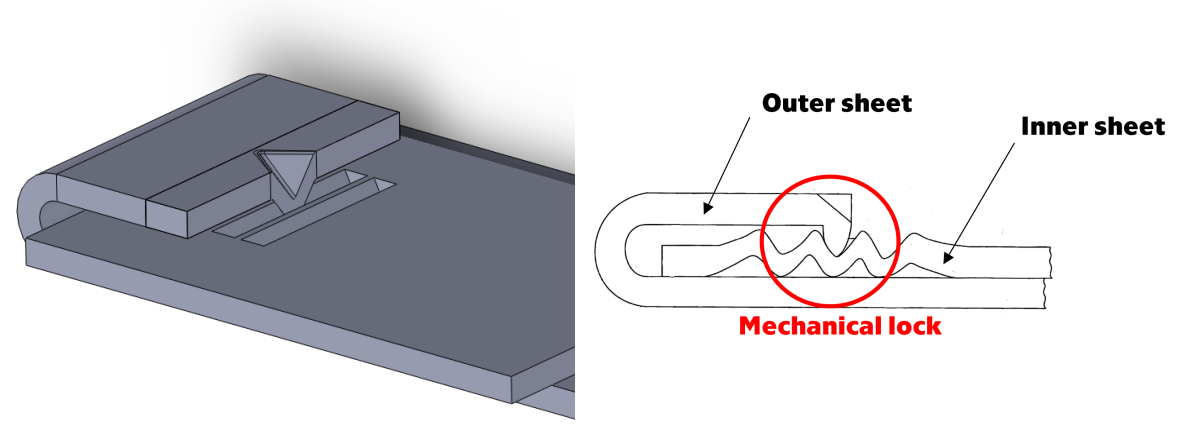

Figure 2. Model of mechanical fixation.
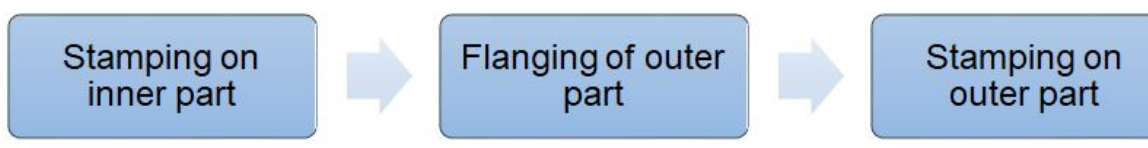

Table hemming

Figure 3. Process scheme.

\begin{tabular}{lccccc}
\hline Material & $R_{e}[\mathrm{MPa}]$ & $R_{m}[\mathrm{MPa}]$ & $A_{80}[\%]$ & $r_{90}[-]$ & $n_{90}[-]$ \\
\hline DX54D & $120-220$ & $260-350$ & 36 & 1.60 & 0.18 \\
\hline
\end{tabular}

TABLE 1. Mechanical properties of the inner part material.

\begin{tabular}{lcccccc}
\hline Material & $R_{p 0.2}[\mathrm{MPa}]$ & $B H 2[\mathrm{MPa}]$ & $R_{m}[\mathrm{MPa}]$ & $A_{80}[\%]$ & $r_{90}[-]$ & $n_{90}[-]$ \\
\hline HX180BD & $180-240$ & 35 & $290-360$ & 34 & 1.50 & 0.16 \\
\hline
\end{tabular}

TABle 2. Mechanical properties of the outer part material.

\begin{tabular}{cccccc}
\hline Strategy & $\mathrm{CE}$ & $\mathrm{CE}+$ & $\mathrm{FV}$ & $\mathrm{UD}_{1}$ & $\mathrm{UD}_{2}$ \\
\hline \multicolumn{2}{c}{ Tolerances and Settings } \\
\hline Stitching Distance [mm] & 0.5 & 0.5 & 0.5 & 0. & 0.5 \\
Meshing Tolerance [mm] & 0.10 & 0.05 & 0.05 & 0.05 & 0.05 \\
Max Side Length [mm] & 50.0 & 30.0 & 10.0 & 10.0 & 10.0 \\
\hline \multicolumn{7}{c}{ Calculation Settings } & & & \\
\hline Radius Penetration [mm] & 0.22 & 0.22 & 0.22 & 0.15 & 0.09 \\
Max Element Angle [ $\left.{ }^{\circ}\right]$ & $30^{\circ}$ & $30^{\circ}$ & $30^{\circ}$ & $22.5^{\circ}$ & $22.5^{\circ}$ \\
Max Refinement Level [-] & 7 & 7 & 6 & 10 & 12 \\
Max Element Size [mm] & 40.0 & 20.0 & 10.0 & 2.0 & 1.0 \\
Min Element Size [mm] & 0.31 & 0.16 & 0.16 & 0.00 & 0.00 \\
Number of Initial elements [-] & 8 & 29 & 114 & 2830 & 11317 \\
Data size [MB] & 42.134 & 42.139 & 45.027 & 49.894 & 70.804 \\
\hline
\end{tabular}

TABLE 3. Simulation strategy settings.

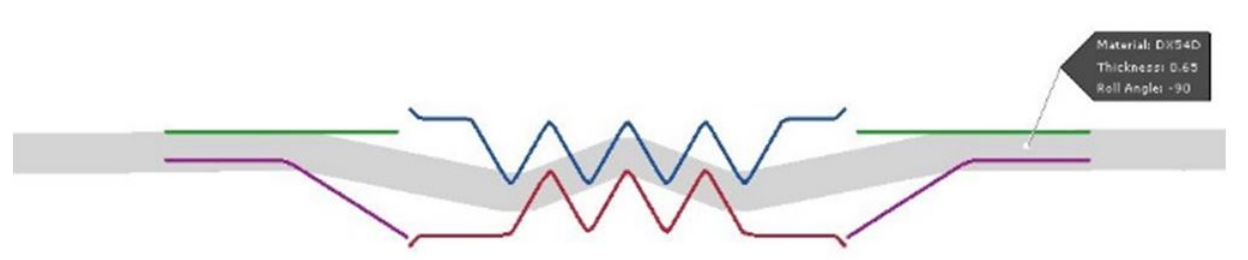

Figure 4. Simulation result from $\mathrm{CE}+$ strategy. 

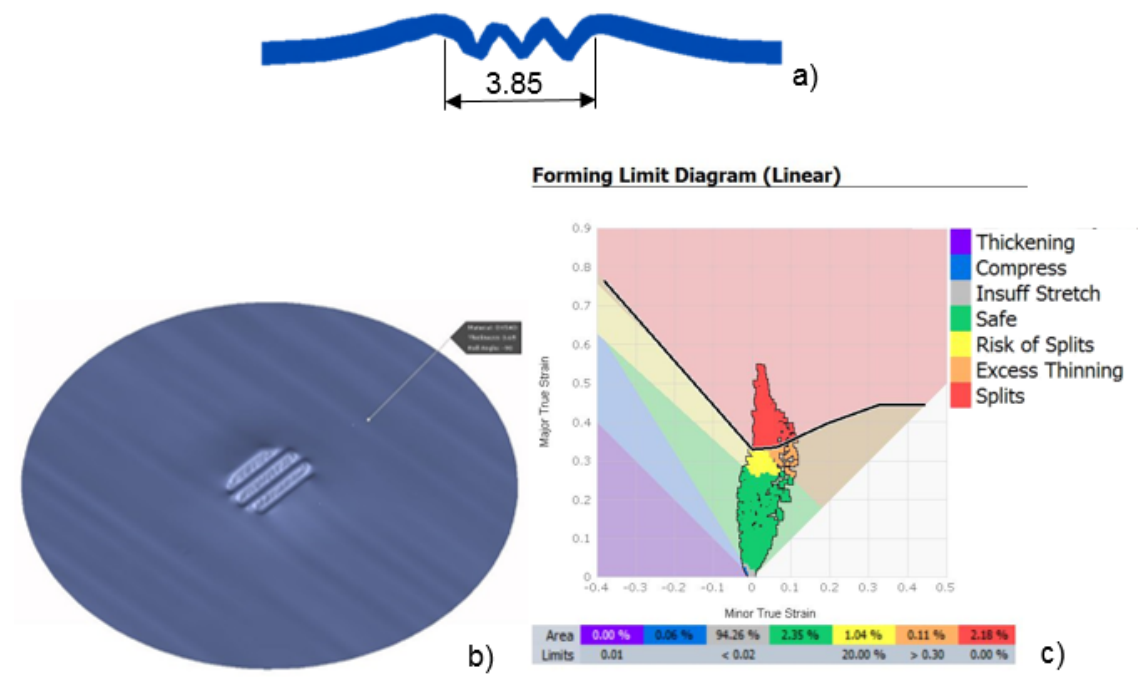

FIGURE 5. Simulation results from Autoform R6 for $\mathrm{UD}_{2}$ strategy (a - width of profile in mm; b - isometric view; c - FLD) $[2$.
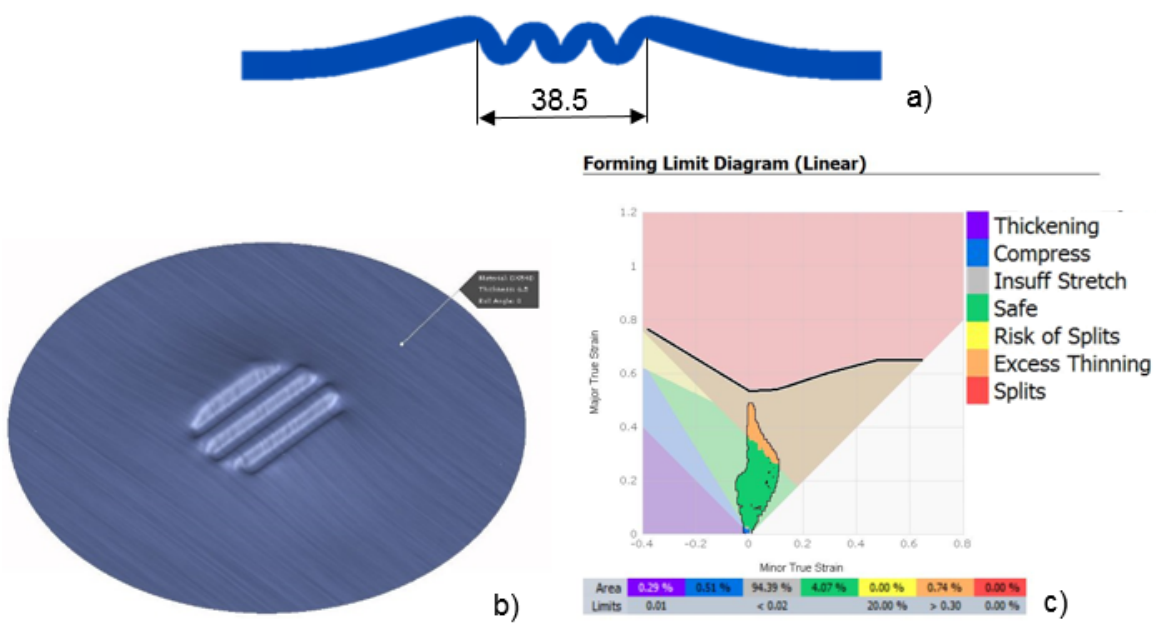

FigURE 6. Simulation results from Autoform R6 after applying the Law of Similarity (a - width of profile in mm; b isometric view; c-FLD) [2].
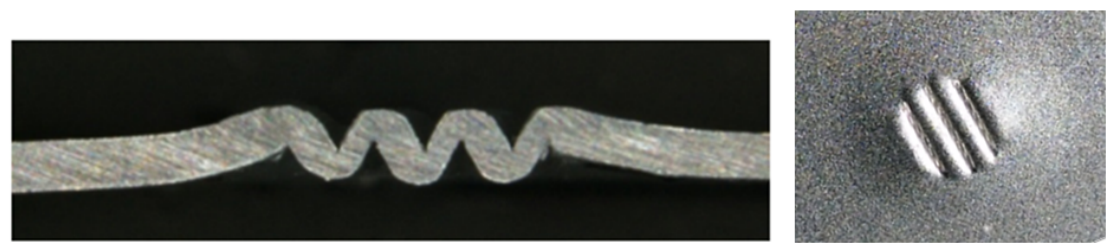

FigURE 7. Experimental sample of grooving. 


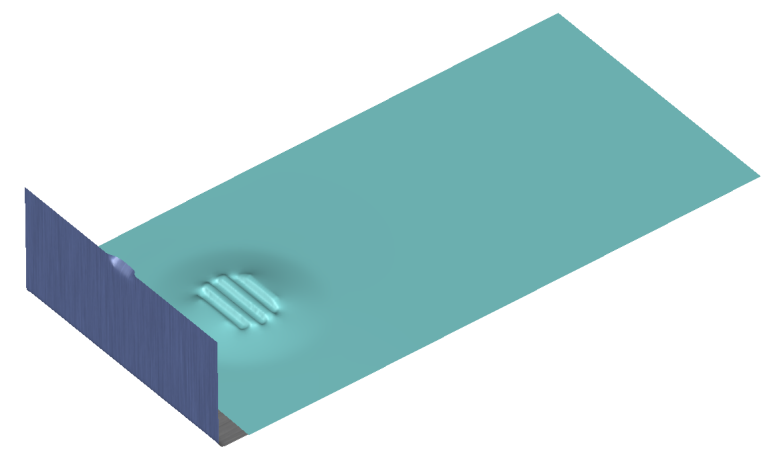

Figure 8. Assembly of the inner part and outer part with fixation elements prepared for hemming.

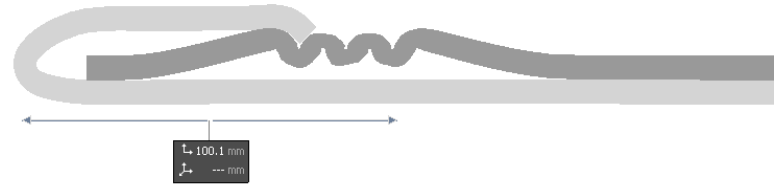

Figure 9. Cross-section view of hemming simulation result after applying the Law of Similarity (material thickness is $6.5 \mathrm{~mm}$ ).

The results from the FEM simulation show that it is possible to use the law in experimental practice. After comparing the result of the simulation (see Figure 6a and 6p), where the ratio of dimensions $10: 1$ to original dimensions was used, with the real experimental sample (see Figure 7), it is obvious that the results from the FEM simulation are correct. The correct results mean an unbroken output from the simulation with the smooth shape of grooving without a material failure. In the FLD, the excess thinning is located, however, on the real experimental sample, the excess thinning is not located and the result is acceptable, so the application of the law is used for the experiment of complete hemming stage (see below). [2

As it was mentioned in the description of the experiment, the whole simulation process follows the proposed operation steps. The whole simulation of the fixation of the hemmed joint is made for one fixation element on the experimental sample after the application of the Law of Similarity. The assembly of the flanged outer sheet with a stamped protrusion and inner sheet with the stamped grooving profile is shown in Figure 8 This assembly is prepared for the last operation - hemming.

\section{Discussion}

Results from the simulation can be compared to the real experimental sample (Figure 10). Samples were performed made onfrom real metal sheets from the same material as that was used for the simulations. From the obtained results, it follows that for a complete simulation of the hemming with a mechanical

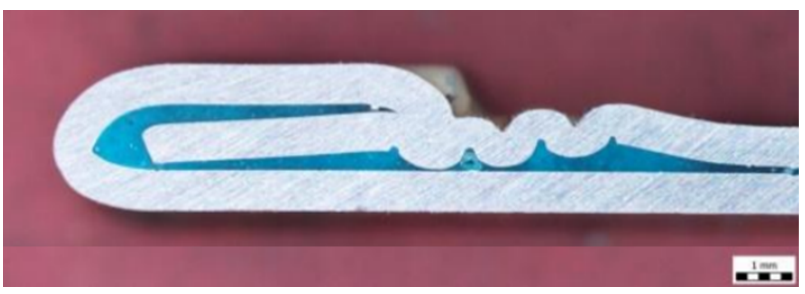

Figure 10. Cross-sectional view of the real hemmed sample with original dimensions (material thickness is $0.65 \mathrm{~mm})$.

fixation, the Law of Similarity can be applied. Before the application of the law, several simulations were made to obtain a comparison of the accuracy of the AutoForm software. When the correct mesh and calculation settings were set up, it was clear that the used simulation software has difficulties to give proper results. The FLD in Figure 5c represents the course of the stamping of the grooving profile of the original dimensions, while the diagram in Figure 6 c shows the course of the grooving profile stamping after application ofapplying the Law of Similarity, where the original tool and blank dimensions are increased by a ratio of $10: 1$. This fact is based on the confirmation of the theory of application of the Law of Similarity, in which the simulation software, despite the precise setting, cannot give the results for the first simulation, i.e. before applying the Law of Similarity. The simulation of the original size of grooves had been calculated without any problems, however, in practice, this solution is unacceptable due to the material failure.

The simulation software used is primarily designed for large parts, and this experiment had been found to be unable too difficult to characterize the material behaviour in detail during the stamping process of small and sharp dimensions.

It follows from the above conclusions that when solving the problems of stamping and drawing of sharp and small geometries, it is always appropriate to perform a simulation of the corresponding process not only for a designed process that only calculates the original dimensions but it is advisable to check the process by a simulation just after the application of the Law of Similarity and then compare both results. If both the FLD trends match and at least one of the simulations finish with acceptable results, that is, without a failure of the material, it can be said that the geometry is manufacturable.

\section{Conclusion}

As is known, numerical simulations are widely used in the process of design for manufacturing of car-body parts and also in the design of stamping tools. Although the FEM simulations for hemming are increasing in the last years, this field is not much explored yet. In this respect, the simulation software is designed only for basic and most common used operations, un- 
fortunately, the FEM software does not involve solving complex tasks for hemming.

One of the main objectives of this article is to verify theof applicability of the AutoForm R6 software for a fixation of hemmed joints. Based on the results, it is possible to say that the current version of the software can be used, but only with a verification after the use of the Law of Similarity. For more detailed results and a final comparison of results, it is necessary to verify the same functionality with newer versions of the Autoform software - R7 and R8. Due to a continuous development in the field of FEM simulations, it can be expected that results from newer versions can give more accurate results for this specific problematics.

\section{ACKNOWLEDGEMENTS}

The research was supported by SGS16/217/OHK2/3T/12. Sustainable Research and Development in the Field of Manufacturing Technology References.

\section{REFERENCES}

[1] L. Chráštanský, J. Hálek, T. Pačák, F. Tatíček. Methodology for mechanical joining of sheets for designing the hemmed joints. In 25th Anniversary International Conference on Metallurgy and Materials (Metal 2016), pp. 345 - 349. TANGER, Ltd., Ostrava, 2016 .

[2] L. Chráštanský, J. Šanovec, Y. Y. Martawirya, M. Valeš. The law of similarity and its application for numerical simulation of sharp geometries stamping. In 27th Anniversary International Conference on Metallurgy and Materials (Metal 2018), pp. 378 - 383. TANGER, Ltd., Ostrava, 2018.

[3] E. Hasegawa, Takeishi, Nakamura. US 2008/0230588 A1 - Electromagnetic hemming machine and method for joining sheet metal layers. Patent, HONDA MOTOR CO., Ltd., Tokyo, 2010.
[4] J. L. Mcclure, S. C. Ramalingam, J. P. Lezotte. US6927370B2 - Hemming working method and panel assembly manufacturing method. Patent, DAIMLERCHRYSLER CORP., 2005.

[5] S. K. Vanimisetti, R. Raghavan, J. E. Carsley. US8341992B2 - Roller hemming with in-situ adhesive curing . Patent, GM GLOBAL TECHNOLOGZ OPERATIONS LLC, 2013.

[6] J. E. Carsley, B. E. Carlson, J. G. Schroth, D. R. Sigler. US20120204412A1 - Method of joining by roller hemming and solid-state welding and system for same. Patent, GM GLOBAL TECHNOLOGZ OPERATIONS LLC, 2012.

[7] J. Rintelmann, B. Hans. DE102013013001 B3 - A method of manufacturing a folding and glueing connection between sheet metal components and component assembly. Patent, AUDI AG, 2013.

[8] M. Polon, Shelby, Mich. US5237734 - Method of interlocking hemmed together panels. Patent, GENERAL MOTORS CORPORATION, Detroit, 1993.

[9] P. Gowling, R. Korda, M. Hradec, J. Hálek. WO/2017/140332 - Sheet metal part assembly. Patent application, AUDI AG and SKODA AUTO, 2017.

[10] R. Cada. Formability of deep-drawing steel sheets. In L. A. J. L. Sarton, H. B. Zeedijk (eds.), Proceedings of the 5th European Conference on Advanced Materials and Processes and Applications (EUROMAT 97): Materials, Functionality 8 Design: Volume 4 - Characterization and Production/Design, pp. 463 - 466. Netherlands Society for Materials Science, Netherlands, Maastricht, 1997.

[11] A. Makinouchi, C. Teodosiu, T. Nakagawa. Advance in FEM simulation and its related technologies in sheet metal forming. CIRP Annals 47(2):641 - 649, 1998.

[12] R. Čada. Technologie I: studijní opora. VŠB Technical University of Ostrava, 2007. 